Vol. 6, Issue 12 (December, 2020)| www.ijaar.org

Journal DOI: 10.46654/ij.24889849

Article DOI: 10.46654/ij.24889849.s61215

\title{
SOCIAL NETWORKING AND EMPLOYEE PERFORMANCE OF MULTINATIONAL OIL COMPANIES IN NIGERIA
}

\author{
Intiedukoba Barry Korubo \\ Department of Management, \\ University of Port Harcourt Business School, \\ Port Harcourt, Rivers State.

\section{B. Chima Onuoha} \\ Department of Management, \\ University of Port Harcourt, Choba, \\ Rivers State, Nigeria.
}

\begin{abstract}
The study evaluates the implication of social networking on employee performance of multinational oil organizations in Nigeria. This is done by identifying the social networking needs and its usage for better performance of employees in selected Multinational companies. Using the purposive sampling technique, the study delimited its scope to Rivers state branches of these various oil firms. A sample size of 50 human resource managers constituted the respondents of the study. Using the regression analysis, the study observes that social networking contributes significantly to employee's performance as captured by the skills learning, knowledge, productivity and motivation. This study shows that social networking become an integral part of respondents' life and have a strong impact on their organizational performance. Social networking affects working situations of employees of multinational oil firms too. The study recommends that managers and those in top administration in M.N.C.s to take part in creating social Networking. It will empower employees to participate in and center on various dynamic to empower associations and their workers to accomplish better execution. Organizations should divide employees in different categories according to their habits of response on social networks and manage their performance productivity accordingly.
\end{abstract}

Keywords: Social Networking, Employee Performance, Multinational firms. 


\section{INTRODUCTION}

Social networking an online medium of interaction which let people build relations, share ideas, communicate information and bounding society in sentimental stream. Social networking is making dramatic growth in dynamic environment of now a day (Pratono, 2018). People use social networks for catharsis of their human emotions. Motives of social networking can be different for person to person like; people connect to LinkedIn for professional purpose, Facebook and Myspace for personal motive, Twitter for social networking, Personalized Blogs for personal thoughts and view point. Motive of using social networks can be change but the ultimate logic of connecting is building social contacts and sharing (Ehrlich, 2011; Ahmad, Bakar, \& Ahmad, 2019). One of the key sectors that dwell on the use of social networking is the petroleum sector, which are operating at the multinational scale.

The petroleum sector, alongside its multinational links is the foundation of the Nigerian economy. Nigeria is the 6th biggest maker of crude oil on the planet. Its oil industry creates more than 95 percent of the nation's private sector revenue and around $80 \%$ of government revenue. The oil business alone makes more than 65,000 direct-jobs in Nigeria and exceeds 250,000 positions in nondirect jobs. The vast majority of the filtration and creation of crude oil are gathered in the Niger Delta. To advance social discourse in the oil and gas industry in Nigeria, social accomplices share the duty of guaranteeing those excellent mechanical relations, solidarity, and profitability reign in the oil segment (Ahmad et al., 2019).

Every organization is using social network sites for their professional benefits like creating customer relationship. So it becomes the need and it's the time for organizations to design workforce according to changing environments. Organization's productivity and profits base on its employee's performance, and its employees are strongly connecting to social networks. In other aspects Social networks are creating risks, opportunities, threats, weaknesses, and strengths for organizations (Pratono, 2018). Risk in a way that social networks are real time communication mediums, It can communicate and disseminate information of organization instantly in real timing which organization may never want to share with people outside the organization. Opportunity in the context that competitor's employee shared information about upcoming strategy at social medium which can be used for organization's benefit. Threat can be faced by organizations when its employees discuss internal information of organization at social networks which can be used by its competitors (Hoque, Awang, Siddiqui, \& Sabiu, 2018). Social networking can be weakness of organization when it affects its productivity negatively. Same social networking become strength for organizations when it's used to build good relationship with employees, to direct them is right way, to collect information about employee behavior and to train them (Flynn, 2011). Based on (Mohamed et al., 2017) Social media has become a necessity in an organization in order to enhance the productivity or job performance among employees. It has been claimed as the effective communication channel among employees to corporate toward collaboration, knowledge sharing, etc. Nevertheless, as the social media became the most priority among individuals and organizations, it has also become one of the factors contributing to the disruption of work productivity. Organizational success largely depends on employees who are considered as the most important assets of any organization because they are capable of creating value and enabling organizations to have a sustainable competitive advantage. Success of any organization depends on the productivity 
of employees. Social media, which has become very popular, has infiltrated the workplace and most employees are utilizing social media in the workplace (Munene et al., 2013).

Knowledge management and communication among the members in any organization play a significant role in improving employee's performance. For several years, researchers have indulged in research work to find different ways to improve the employee's performance. Social networking affect the petroleum industry as it affecting employee's skills, productivity, qualification/knowledge and motivational level. Multinational oil firms practice social networking for building employeremployee relationship by increasing employee's skills, productivity, motivational level and knowledge. Multinational oil firms evaluate their employees and manage their contributions to keep Multinational oil companies' image high through social networking. Multinational oil firms direct their employees for ethical behavior in using social networks while they are representatives of the organization. For doing all this multinational oil firms are formulating some sort of policies regarding using of social networking. According to the above discussion, it can be said that social networking has strong impact on employees' performance in terms affecting skills, productivity, knowledge and motivation. This study is conducted in Nigerian multinational oil firms, either at what extent they are using social networking to increase skills, knowledge, productivity and motivation of their employees.

\section{- Statement of Problem}

Studies on the influence of social media and the use of it in Nigeria, with a special focus on the operations of the multinational firms, are not that many. Employees are applying the social media platforms in the workplace as a daily routine and it becomes very important to identify the influence and effect of these tools on employees' performance. Over the last few years, the fast development of social media that has been watched reflects its significance and coordination in numerous individuals' daily life activities. As per Warnakula, and Manickam (2014), most of the employees visit Social networking sites during their available time at work. There is an extensive discussion among Business experts and researchers on the value of social networking site usage in the working environment. Some researchers claim that social media use in the work environment is an exercise in futility, while others trust it prompts enhancements in work execution. This study endeavours to determine this debate by inspecting the utilization of social networking sites in the work environment and its impact on employee's performance. In the past, a few studies have been conducted on using social media usage at the workplace and their moral and ethical implications (Clark \& Roberts, 2010) to security and privacy issues (Dinh, 2011; Dwyer et al., 2007; Patel \& Jasani, 2010).

Multiple studies have been undertaken to examine whether the usage of social networking sites in the work environment has any potential advantages for organizations and employee's performance. Hence, this study endeavors to fill this gap by analysing whether the usage of social networking sites in the work environment adds to employee performance in Multinational oil organizations in Nigeria. It is essential for the managers to decide concerning whether social Networking in the working environment impacts employee's performance in their business. To the best of the researcher, no examination has been directed so far in Nigeria to analyse whether social Networking in the working environment prompts employee's performance concerning Nigerian Oil Sector. This creates a knowledge gap, which turns into an issue to managers with respect to the social networking 
utilization of workers. Researchers have analyzed this issue in this study and endeavors to fill this information gap and endeavors to determine the contention by inspecting the usage of social networking sites in the working environment and its impact on employee's performance.

The purpose of this study is to explore that either social networking have impact at employee performance variables like knowledge, abilities/skills, productivity and motivational level. Here is the study undertaken in Nigerianthe petroleum industry to assess how social networking impacting at employee performance. This study checks that multinational oil firms use social networking to intact their employees with organization by increasing their motivational level. Multinational oil firms use social networks to share latest information with its employees at real time for increasing productivity and knowledge of employees. This study also investigates the phenomenon that either multinational oil firms use social networks as training tool for increasing abilities or skills of its employees.

\section{LITERATURE REVIEW}

\subsection{Theoretical Framework}

The study is anchored on the Person-Environment Fit Theory.

\subsubsection{Person-Environment Fit Theory}

This theory as developed by Edqard, Caplan and Van Harrison (1998) focuses on the interaction between characteristics of the individual and the environment, whereby the individual not only influences his or her environment, but the environment also affects the individual (see earlier discussion of transactional models). In light of social networking, this theory says that the right social networking is needed to ensure that employee performance wonderfully well. The adequacy of this fit between a person and the environment can affect the person's motivation, behavior, and overall mental and physical health163; that is, if the fit is optimal, the individual's functioning may be facilitated; if it is unsuitable, the individual may experience maladaptation. For example, a developmental-behavioral paediatrician may learn that a particular school environment is not providing much needed academic programming for an academically at-risk child. The clinician can intervene, the goal being to maximize the fit between the child's needs and the schools programming. The importance of person-environment fit with parents can provide a useful rationale when a particular intervention is recommended (Pratono, 2018).

\subsection{Conceptual Framework}

\subsubsection{Social Networking}

Social networking is the use of Internet-based social media sites to stay connected with friends, family, colleagues, customers, or clients. It exists in the form of Communication between companies, associates or peers, where channels specific for the professional world, social networks like LinkedIn or Zoom, are used to establish ties with professionals in the same industry. Social networking can have a social purpose, a business purpose, or both, through sites such as Facebook, Twitter, LinkedIn, and Instagram, among others. Social networking has become a significant base for marketers seeking to engage customers. Marketers use social networking for increasing brand recognition and encouraging brand loyalty (Rialp-Criado \& Rialp-Criado, 2018). Since it makes a company more accessible to new customers and more recognizable for existing customers, social 
networking helps promote a brand's voice and content. Customers may complement the company's offerings and encourage others to buy the products or services. The more customers are talking about a company on social networking, the more valuable the brand authority becomes. As a brand grows stronger, more sales result. Increased company posts rank the company higher in search engines. Social networking can help establish a brand as legitimate, credible, and trustworthy. A company may use social networking to demonstrate its customer service level and enrich its relationships with consumers (Ahmad, Bakar \& Ahmad, 2019).

\section{- Dimension of Social Network}

Usefulness: -It is the extent to which an individual believes utilizing a specific system would improve his job performance. Usefulness is the discernment that a particular technology will enable a user to accomplish their work goals. Usefulness alludes to the outside advantages to the userframework collaboration, which is improving the job performance. Alternatively, people will use a particular framework only when they see its use would help them accomplish the ideal performance.

Ease of Use: - Ease of use alludes to how much mental exertion is exhausted in the use of the framework. The user evaluates the Ease of use through the cooperation with the framework instead of through the association with the framework. Maybe an individual solid on creativity may be an impression of liberality for new applications, including Social Networks, considering them simple to use (Venkatesh \& Bala, 2008). Vankatesh (2000) deduced in his examination that the innovation acknowledgment model would be useful because it is perceived by the user to be simple.

Subjective Norms: - Subjective standard alludes to social pressure to use any technology. It results from a well-established belief of behaving (standardizing convictions) and a person "s level of inspiration to agree to those convictions (Davis, Bagozzi, and Warshaw, 1989). Subjective Norm was not part of the first Technology Acceptance Model, yet was added later to help clarify the impact that co-workers and different workers have on a person's behavior.

\subsubsection{Employee Performance}

Employee performance is defined as how an employee fulfils their job duties and executes their required tasks. It refers to the effectiveness, quality, and efficiency of their output. Performance also contributes to our assessment of how valuable an employee is to the organization (Pradhan \& Jena, 2017). One of the most important factors in employee performance is to achieve goals. Successful employees meet deadlines, make sales and build the brand via positive customer interactions. When employees do not perform effectively, consumers feel that the company is apathetic to their needs, and will seek help elsewhere. Employees who perform effectively get things done properly the first time. Imagine if the person who created customer reports was always late in completing them. The client services department would always be waiting, looking unprofessional, and perhaps incompetent (Hoque, Awang, Siddiqui, \&Sabiu, 2018).

\subsection{Empirical Literature}

Literature was reviewed with respect to this study. This remembers past study for performance the board of employees, its factors, social Networking, and its effect on the employee's performance.

AlBuflasa (2019) investigated the influence of social media factors on various performance measures within the telecommunication company ZAIN BAHRAIN ("ZAIN BAH") based in 
Nigeria. This Study decided on Trust, Shared Vision and Network Ties as the factors of Social Media based on the literature review and its influence on employee's performance. This study has shown that different Social Media factors influence employee's performance outcomes. It is recommended that ZAIN BAH should keep implementing Social Media practices with all variables taking into account the Social Media factors that influenced the overall employees' performance.

Ashraf and Javed (2014) evaluated the impact of social networking like Facebook, Twitter, Slideshare, Linkedin, etc at employee's performance. The study's model showed that social networking affects the productivity, skills, knowledge, productivity and motivational level of employees of multinational oil firms. Data is collected from different Multinational oil companies' employees so that the real scenario can be presented. Data collected from The Bank of Punjab Pakistan, National Bank of Pakistan and Habib Bank of Pakistan. This showed that using of social networking have strong impact on employee performance.

Somani and Gupta (2012) locate that many organizations attempt to keep workers working with high motivational levels in their daily work. Organizations save close contact with their employees for their performance on the board. Presently a day's social Networking assumes a part of the day by day journal in each one's life. Companies can view worker's social networking activities to screen their performance. For performance surveys, drawing in employees inside organization activities and sharing association's data can make informal social organization groups.

Collins and Clark (2003) find that top administration's utilization of social organizations constructs the organization's upper hands. They state that organizations intentionally create social organizations through H.R. This method makes a solid connection between top administration and employees and improves employee performance.

Bosch (2009) found in their study that organizations plan worker training programs dependent on social Networking, which help their H.R. workforce instruct, learn and share data on an ongoing basis and give feedback. These performance training methods have a substantial effect on worker performance.

Liu and Lee (2010) clarify that employee's social networking data is unequivocally identified with worker performance and teams up with separating employee's performance. Organizations utilize social organizations in creating human resources rehearses.

\section{METHODOLOGY}

This study dwells on the cross-sectional research design. A research survey was conducted to evaluate the relationship between social networking and employee's performance according to presented model of relationship between Social Networking and Employee Performance of multinational oil companies in Nigeria. More than a million employees were working in the organizations at the time of data collection. Convenience sampling, which is the most convenient sampling strategy, was chosen for this research. It is simple for conducting a survey and monetarily less expensive as less time is taken to get the information. From survey, the sample total of 70 human resource managers were estimated, out of the 70 human resource managers, only 50 correctly complete questionnaires were received. These questionnaires were obtained from the branches of various multinational firms located in Rivers State. The questionnaires were distributed to 
respondents over various periods. In this survey, judgment sampling was taken to distribute questionnaires to employees who represent the key human resource management personnel. For survey all form of multinational oil firms were considered. Personal contacts were used for data collection, explaining motives to respondent of survey and ensuring them that instrument will reach the target.

Survey method was adopted to collect primary data for current issue. The questionnaire was structured and containing close ended questions. Statistical package for social sciences version 25 was employed in order to do analysis of collected primary data for research. Significance of questionnaire was checked. Reliability of the scale was counted. Correlation and Regression analysis were employed for drawing results.

\section{RESULTS AND DISCUSSIONS}

Table 1 shows the reliability and consistency in the data set; from the table, we can find that the value of Cronbach's alpha is greater than 0.705 and 0.795 for social networking and Employees performance, which is greater than the acceptable limit of 0.7. Hence we can say that the data set taken for the research purpose is consistent.

Table 1: Reliability Statistics

\begin{tabular}{l|c}
\hline Variables & Cronbach's Alpha $^{\mathrm{a}}$ \\
\hline Social Networking & 0.705 \\
\hline Employees Performance & 0.795 \\
\hline
\end{tabular}

\section{- Correlation Analysis of Data}

This paper measure the correlation of social networking with employee's skills, knowledge, productivity and motivation. Table 2 shows positive correlation between social networking and four factors of employee's performance (skills, knowledge, productivity and motivation). The correlation was positive and significant at the level of 0.01 to 0.05 between social networking and skills, productivity, knowledge, motivation. For Example, Correlation between social networking and Employee's skills $0.639(\mathrm{p}=0.000)$; the correlation between social networking and employee's knowledge was $0.480(\mathrm{p}=0.000)$; the correlation between social networking and Employee's productivity was $0.384(\mathrm{p}=0.006)$; the correlation between social networking and Employee' motivation was $0.646(\mathrm{p}=0.000)$. 
Table 2. Correlation of Social networks with Skill, Knowledge, Productivity, Motivation

\begin{tabular}{|l|l|l|l|l|}
\hline & Measures & Correlation & Social Networking & Decision \\
\hline $\mathbf{1}$ & Skill & Sig & 0.000 & Reject H0 \\
\hline $\mathbf{2}$ & & Correlation & 0.48 & \\
\hline $\mathbf{3}$ & Knowledge & Sig & 0.000 & Reject H0 \\
\hline $\mathbf{4}$ & Productivity & Correlation & 0.384 & Reject H0 \\
\hline & & Sig & 0.006 & \\
\hline
\end{tabular}

**. Correlation is significant at the 0.01 level (2-tailed).

Therefore the results indicate that correlation between dependent and independent variables was strongly positive. Employee's skills, knowledge, productivity, and motivation highly correlate with using of social networks. Social networking has impact $64 \%, 48 \%, 38 \%$ and $65 \%$ on skills, knowledge, and productivity and motivation level of employee's respectively. So this correlation can be improved more with little efforts of multinational firms' managements. These results explore and support to accept the first hypothesis that there is positive relation between use of social networking and employee's performance variables (skills, Knowledge, Productivity, and Motivation).

\section{- Regression Analysis of Data}

Regression model employed to predict the factors affected by using of social networks. In regression analysis four dimensions are undertake as dependent variables in terms of employee's skills, knowledge, productivity and motivation. Table 3 shows the Regression coefficient between dependent variable (X1= Employee Skills) and independent variable using of Social Networking, the regression $\mathrm{R}$ was 0.639 . It represents the association of using social networks and employee skills $63.9 \%$. High value of beta and level of significance shows the strength of association. From table 2 dependent variable (X2=Employee Knowledge) and independent variable Social Networking, the regression $\mathrm{R}$ was 0.480 . So it shows the association between using social networking and employee knowledge $48 \%$. Highly beta and strongly significant these variables were. By table 2 dependent variable (X3=Employee Productivity) and independent variable Social Networking, the regression $\mathrm{R}$ was 0.384 . Association was between using social networking and employee productivity was $38.4 \%$. Significance is little weak but still positive between these variables. In table 3 dependent variable (X4=Employee Motivation Level) and independent variable Social Networking, the regression $\mathrm{R}$ was 0.646 . Dependent and independent variable association here become $64.6 \%$. Here again highly significant and having high beta. 
Table 3. Regression Analysis of Factors Affected by using Social Networks

\begin{tabular}{lllllllll} 
Dimensions & $\mathbf{R}$ & $\mathbf{R}^{2}$ & $\begin{array}{l}\text { Adjusted } \\
\mathbf{R}^{2}\end{array}$ & $\begin{array}{l}\text { Std. } \\
\text { Error }\end{array}$ & $\begin{array}{l}\text { Unstandardized } \\
\text { coeff }\end{array}$ & $\begin{array}{l}\text { Std } \\
\text { Coefficient }\end{array}$ \\
\hline Skills & 0.639 & 0.408 & 0.396 & 0.60296 & 0.754 & 0.639 & 0.000 \\
\hline Knowledge & 0.48 & 0.23 & 0.241 & 0.61773 & 1.292 & 0.48 & 0.000 \\
\hline Productivity & 0.384 & 0.148 & 0.13 & 0.87005 & 1.364 & 0.384 & 0.006 \\
\hline Motivation & 0.646 & 0.418 & 0.406 & 1.73988 & -2.443 & 0.646 & 0.000
\end{tabular}

This finding shows that using social networking contributes to employee's skills learning, gaining knowledge, and becoming more productive for organization and increase in motivation level. Results shows that dimension of skills learning was $63.9 \%$, gaining knowledge was $48 \%$, productivity was $38.4 \%$ and motivation level increase was $64.6 \%$. It means that there can be other contributing factors exist too. There can be still margin for improvement too.

These results show that these four dimensions get affected by using of social networking. This affect contribute to employee performance positively. In Nigeria, multinational oil firms sector can use this model to enhance the performance of its employees. Multinational oil firms can enhance their employee skills/ multi-tasking, make them employee with more knowledge, increase motivational level and bring more productivity in work.

\section{CONCLUSION}

Conclusively, the study observes that social networking contributes significantly to employee's performance as captured by the skills learning, knowledge, productivity and motivation. Exploring the presented issue has a large implication for multinational oil firms. Especially it carries interest for human resource (HR) departments who have concern for employee's performance. First, multinational oil firms should focus on employee's behavior towards using social networks. Multinational oil firms can design their training programs according to habits of using social networks of employees. For example, multinational oil firms can make social media accounts and use it for training purpose. HR department can update its policies, new training programs, meeting schedules, training tools, inspirational quotes on Facebook training page.

Secondly, Multinational oil companies' HR department can use Facebook or other social network profiles of employees to screen out required skills for newly launched/planned project. Multinational oil firms can use these social networks to enhancing skills/ abilities, knowledge/qualification, productivity/outcomes and motivation level of employees. Multinational oil firms can create the right directions of usage of social networks by employees.

On the other hand, multinational oil firms should develop right attitude in its employees for using social networks. It should be taken as positive and ethical medium of social communication. Multinational companies' employees should take social networks as a constructive medium for learning new things, ideas, creating social contacts, having emotional catharsis instead of destructive medium or behaving below morality. At social networks, employees are representative/ symbol of the various multinational companies. Their below morality activity or behavior can spoil the image of multinational companies in spectator's point of view. So, multinational oil firms can avail social 
networking platforms for developing and enhancing employee's performance. Importantly, there can be some unknown factors too which can affect impact of using social networks on employee performance. Which suggest grounds like positive or negative behavior of employee, lazy attitude of employee, wrong perception while reading status updates, etc. These variables can provide ground for further investigations. This model assists multinational oil firms for designing employee training programs and making training program more interesting, attractive and matching to young generation's behavior.

In light of the findings of the study, it is highly recommended that managers and those in top administration in M.N.C.s to take part in creating social Networking. It will empower employees to participate in and center on various dynamic to empower associations and their workers to accomplish better execution. Organizations should divide employees in different categories according to their habits of response on social networks and manage their performance productivity accordingly. 


\section{References}

Ashraf, N., \&Javed, T. (2014). Impact of social networking on employee performance. Business Management and Strategy, 5(2), 139-150.

Edwards, J. R., Caplan, R. D., \& Van Harrison, R. (1998). Person-environment fit theory. Theories of organizational stress, 28, 67.

Pratono, A. H. (2018). From social network to firm performance. Management Research Review. $4(6), 18-22$.

Rialp-Criado, A., \&Rialp-Criado, J. (2018). Examining the impact of managerial involvement with social media on exporting firm performance. International Business Review, 27(2), 355-366.

Ahmad, S. Z., Bakar, A. R. A., \& Ahmad, N. (2019). Social media adoption and its impact on firm performance: the case of the UAE. International Journal of Entrepreneurial Behavior\& Research.

Ramkumar, P. N., Navarro, S. M., Haeberle, H. S., Chughtai, M., Flynn, M. E., \& Mont, M. A. (2017). Social media and total joint arthroplasty: an analysis of patient utilization on Instagram. The Journal of Arthroplasty, 32(9), 2694-2700.

Pradhan, R. K., \& Jena, L. K. (2017). Employee performance at workplace: Conceptual model and empirical validation. Business Perspectives and Research, 5(1), 69-85.

Hoque, A. S. M. M., Awang, Z. B., Siddiqui, B. A., \&Sabiu, M. S. (2018). Role of employee engagement on compensation system and employee performance relationship among telecommunication service providers in Bangladesh. International Journal of Human Resource Studies, 8(3).

AlBuflasa, N. Z. M. (2019). The Use of Social Media and its Influence on Employee Performance: The Case of Zain Bahrain. International Journal of Innovative Science and Research Technology. 4(4), 5-10.

Patel, N., \&Jasani, H. (2010). Social media security policies: Guidelines for organizations.

Pulakos, E. D., Arad, S., Donovan, M. A., \&Plamondon, K. E. (2000). Adaptability in the workplace: development of ataxonomy of adaptive performance. Journal of applied psychology, 85(4), 612.

Pulakos, E. D., Dorsey, D. W., \& White, S. S. (2006). Adaptability in the workplace: Selecting an adaptive workforce. Advances in Human Performance and Cognitive Engineering Research, 6, 41.

Rawlings, S. 2007. The Multinational Companies: Instrument for WorldGrowth" Journal of Commerce 5 (2), 25-33

Sanders, N.R. (2007). An empirical study of the impact of e-business technologies on organizational collaborationand performance. Journal of Operations Management, 25(6), 1332-1347. 
Shami, N.S., Nichols, J., \& Chen, J. (2014, April). Social media participation and performance at work: A longitudinal study. In Proceedings of the S.I.G.C.H.I. Conference on Human Factors in Computing Systems (pp. 115-118).

Stollak, M., Vandenberg, A.S., Felhofer, N., \& Sutherland, P. (2014). How social media is influencing the job search process. Journal of Management and Marketing Research, 15, 1-7. Retrieved from http://www.aabri.com/ manuscripts/141817.pdf (March 2018).

Bosch, T. E. (2009). Using Online Social Networking for Teaching and Learning: Facebook Use at the University of Cape Town. Communicatio: South AfricanJournalfor Communication Theory and Research, 35(2), 185-200. http://dx.doi.org/10.1080/02500160903250648

Castilla, E. J. (2005). Socail Networks and Employee Performance in a call Center1. JSTOR: American Journal of Sociology, 110(5), 1243-83. http://dx.doi.org/10.1086/427319

Collins, C. J., \& Clark, K. D. (2003). Strategic Human Resource Practices, Top Management Team Social Networks, and Firm Performance: The Role of Human Resource Practices in Creating Organizational Competitive Advantage. Academy of Management Journal, 46(6), 740-751. http://dx.doi.org/10.2307/30040665

Ehrlich, S. Z. (2011). How social media affects HR: Uses. Abuses and Self-Protection. [Online] Available: http://fiveoclockclub.com/how-social-media-affects-hr-uses-abuses-and-selfprotection/

Liu, F., \& Lee, H. J., (2010). Use of Social Network Information to Enhance Collaborative Filtering Performance. Expert Systems with Applications, 37(7), 4772-4778. http://dx.doi.org/10.1016/j.eswa.2009.12.061

Mehra, A., et al. (2001). The Social Networks of High and Low Self-Monitors: Implication for Workplace Performance. SAGE Journal, 46(1), 121-146. http://dx.doi.org/10.2307/2667127

Purdy, C. Social Media is Revolutionising HR and Recruitment Strategies. [Online] Available: http://www.greenfield.lu/employees-newsarticles/25-social-media-is-revolutionising-hr-and-r ecruitment-strategies.html/

Sokoll, W., \& Press, J. (2012). Human Capital Gets Personal With Social Media. CIO Journal.

Somani, V., \& Gupta, A. (2012). Social Networking and Its Impact on Human Capital Management in FMCG Sector. [Online] Available: http://www.mbaskool.com/businessarticles/human-resource/5498-social-networking-a-its-impact-on-human-capital-managementin-fmcg-sector.html/

Sparrowe, R. T., et al. (2001). Social Networks and Performance of Individuals and Groups. Academy of Management Journal, 44(2), 316-325. http://dx.doi.org/10.2307/3069458 